\title{
Self-reported physical activity behavior of a multi-ethnic adult population within the urban and rural setting in Suriname
}

\author{
Se-Sergio M Baldew ${ }^{1,2^{*}}$, Ingrid SK Krishnadath ${ }^{3}$, Christel CF Smits ${ }^{3}$, Jerry R Toelsie ${ }^{4}$, Luc Vanhees ${ }^{2 \dagger}$
} and Veronique Cornelissen ${ }^{2 \dagger}$

\begin{abstract}
Background: Physical activity (PA) plays an important role in the combat against noncommunicable diseases including cardiovascular diseases. In order to develop appropriate PA intervention programs, there is a need to evaluate PA behavior. So far, there are no published data on PA available for Suriname. Therefore, we aim to describe PA behavior among the multi-ethnic population living in urban and rural areas of Suriname.

Methods: The World Health Organization (WHO) STEPwise approach to chronic disease risk factor surveillance (STEPS) was conducted in a national representative sample ( $N=5751 ; 48.6 \%$ men) aged 15-64 years between March and September 2013. Physical activity data were assessed using the Global physical activity questionnaire (GPAQ) and analyzed according to the GPAQ guidelines. The prevalence of meeting the recommended PA level and prevalence ratios (PR) were computed.
\end{abstract}

Results: Only 55.5\% of the overall population met the WHO recommended PA levels (urban coastal area: 55.7\%, rural coastal area: $57.9 \%$, rural interior area: $49.1 \%)$. Women were less likely to meet the recommended PA level (49\% vs 62.4\%; $p<0.0001)$ and with increasing age the PR for recommended level of PA decreased $(p<0.0001)$. Compared to the Hindustani's, the largest ethnic group, the Javanese reported the lowest percentage of people meeting recommended PA level $(P R=0.92 ; p=0.07)$.

Conclusion: Around half of the population meets the recommended PA level. Future lifestyle interventions aiming at increasing PA should especially focus on women and older individuals as they are less likely to meet the recommended levels of PA.

Keywords: Self-reported physical activity, Multi-ethnic population, WHO STEPS, Global physical activity questionnaire

\section{Background}

Cardiovascular diseases (CVD) remain the number one cause of death globally, with over $80 \%$ of these deaths reported in low and middle income countries [1]. In prevention of cardiovascular and other noncommunicable diseases (NCD), physical activity (PA) plays an important role [2-4].

\footnotetext{
* Correspondence: sergio.baldew@uvs.edu

${ }^{\dagger}$ Equal contributors

'Department of Physical Therapy, Faculty of Medical Sciences, Anton de Kom University of Suriname, Paramaribo, Suriname

${ }^{2}$ Department of Rehabilitation Sciences, Research Center for Cardiovascular Rehabilitation, Faculty of Kinesiology and Rehabilitation Sciences, Katholieke Universiteit Leuven, Leuven, Belgium

Full list of author information is available at the end of the article
}

In contrast to what is known about PA in Europe [5,6] and North America [7] there are no published PA data available for Suriname. However, 27\% of all deaths in Suriname are caused by cardiovascular diseases, making them the number one cause of mortality [8].

There is an obvious need for an adequate evaluation of PA behavior in order to initiate and implement appropriate PA intervention programs in Suriname. Since Suriname has a diverse ethnic population and the prevalence of CVD and risk behaviors associated with these diseases has been shown to differ among ethnic groups [9-11], evaluation of PA behavior across the ethnic groups needs to be taken into account. 
In addition to the large variability between countries with regard to the proportion of individuals meeting the recommended PA level [12,13], it has also been shown that these levels might differ within a country depending on the area $[13,14]$. In general, individuals living in urban areas tend to be less active compared to those living in rural areas [14-18], although one report concluded the opposite [19].

Therefore, if we aim to develop effective interventions to increase PA behavior, it is important to take all these differences, i.e. ethnicity and area into account. Thus, the main objective of this study was to describe PA behavior in a representative sample of the Surinamese population, across urban and rural areas. Secondly, we aimed to investigate whether there are differences in PA among the different ethnic groups.

\section{Methods}

This cross-sectional study was based on the WHO STEPwise approach to Chronic Disease Risk Factor Surveillance (STEPS) protocol. A detailed description of the study design and participant recruitment has been reported elsewhere [20]. Briefly, a sample size was calculated based on area, gender distribution and on five age groups between 15 and 64 years. Furthermore, ethnic groups were taken into account to ensure a sufficient number of participants could be drawn from each subgroup. A stratified, multi-stage, cluster, sampling design was used to select households within the different areas. From March to September 2013, 7493 individuals from urban and rural areas were invited to participate, of which 5751 agreed (response rate: 76.8\%) and provided written informed consent [20]. For participants under the age of 16, parental informed consent was obtained. The study was approved by the ethical committee of the Ministry of Health in Suriname.

\section{Physical activity assessment}

Trained interviewers used the Global physical activity questionnaire (GPAQ) to assess PA [21]. This questionnaire was first translated into Dutch and pre-tested in a small study sample for reliability and face-validity $[22,23]$. Interviewers asked participants about the number of days and the time they spent doing PA in a typical week within 3 main domains: occupation, transportation and leisure time. Within the occupation domain the activity had to be performed as part of paid or unpaid work, whereas within the transportation domain, PA included walking and/or cycling in order to move from one place to another. Leisure time activities involved all activities that were not included in the occupation or transportation domain. To be considered as an activity, it had to be performed for at least
10 minutes continuously. For activities during occupation and leisure time, participants were asked if it was performed at moderate or vigorous intensity. In order to categorize the activity within the appropriate intensity, examples were given by means of illustrations. Moderate activities were described as activities that cause a small increase in breathing and heart rate, whereas vigorous activities should result in a large increase in breathing and heart rate. For activities within the transportation domain, participants were asked if they walked or cycled at a moderate intensity for at least 10 minutes continuously.

We used the GPAQ analysis guide, provided by the WHO, to clean and analyze the data [24]. According to the guidelines, the data should be excluded if the time spend within a subdomain exceeds 16 hours or participants reported inconsistent or implausible values. Individuals who accumulated throughout a week at least 150 minutes of moderate or vigorous intensity physical activity or an equivalent combination over at least 5 days in the week or 75 minutes of vigorous intensity physical activity on at least 3 days of the week were classified as meeting the recommended PA level. This could be achieved within only one domain or by a combination of the three.

\section{Socio-demographic information}

We divided the country into three areas: the urban coastal area (UCA), the rural coastal area (RCA) and rural interior area (RIA) as defined by the General statistics bureau in Suriname [25]. The RIA is characterized by remote villages within the hinterland, whereas the RCA is less remote, situated near the coast, but does not have all the characteristics of an urban area. Furthermore, participants were categorized based on monthly household income and educational level.

\section{Ethnicity}

For the current analysis we only included the 5 largest ethnic groups: Hindustani, Creole, Maroon, Javanese and mixed ethnicity. The participant's ethnicity was defined based on self-reported ethnicity of the four grandparents. If at least 3 grandparents were from one ethnic group the participant was classified within that specific ethnic group or else within the mixed ethnicity group [20]. South Asian descendants, mainly from the Indian subcontinent are referred to as the Hindustani population, whereas descendants from Java, Indonesia are referred to as Javanese. For African descendants a distinction was made between descendants that, during slavery remained in the city referred to as the Creole [26], and those that escaped into the hinterland, referred to as Maroons $[20,27,28]$. 


\section{Statistical analysis}

In order to have a representation from the Surinamese population, the data were weighted. The weights were calculated to adjust for probability of selection; nonresponse and differences in age, gender and ethnicity between the sample population and target population. The data from the census 2012 was used as target population [20]. Statistical analyses were performed using SPSS (version 21; SPSS for windows; SPSS Inc, Chicago, IL). Categorical data are presented as numbers (\%) and were analyzed using the chi-square test; continuous data as median and mean \pm standard deviation (SD).

Unadjusted and adjusted prevalence ratios were calculated for area, gender, age categories and ethnicity, by poisson regression. Because of missing data on income, information of 3255 (72.5\%) individuals was included in the regression model. Adjustments were made for area, gender, age categories, level of income and education. A p-value (two-sided) $\leq 0.05$ was considered statistically significant.

\section{Results}

Before data cleaning, the study sample included 5751 subjects. Of those, 3 records were not valid and almost $1 \%$ of the PA data was missing $(n=57)$ [20]. Following the GPAQ guidelines [24] we excluded an additional 779 participants for the following reasons: time reported for an activity exceeded 16 hours per day $(n=9)$; total hours of PA over the 7 days exceeded 168 hours $(n=23)$; implausible or inconsistent values were reported $(n=747)$. Data were considered implausible if there was a mismatch between the reported number of days and the time spend active on those days. For instance, the participant reported to be active for a certain period of time, but the reported number of days was zero or missing. Finally, missing data on ethnicity and participants belonging to other groups than the included ethnic groups $(n=428)$, were excluded, resulting in 4487 valid records.

Table 1 shows the number of subjects and the weighted percentages per area. Overall, the majority $76.0 \%$ lived within the UCA with only $15.9 \%$ and $8.1 \%$ of the population living in the RCA and RIA respectively. Approximately half of the population was male (48.6\%) and the average age was 36.2 years (range 15 to 64 ). There was an equal distribution of men and women $(p>0.05)$ within and between the three areas; no significant differences were observed regarding age $(p>0.05)$. However, there were significant differences between the areas with regard to ethnicity with the majority of individuals in the UCA and RCA being of Hindustani origin and the Maroons constituting the largest ethnic group in the RIA. In addition, the economic status and level of education also differed between the areas, whereby a larger proportion of individuals without an income and with no official education lived in the RIA $(\mathrm{p}<0.05)$.

Regarding PA, 55.5\% $(\mathrm{n}=2377)$ of the total population met the WHO recommendations. Further, compared to individuals from the UCA, individuals living within the RIA were less likely to meet the recommended PA levels, whereas the prevalence of meeting these recommendations was higher for individuals living in the RCA ( $p$ for trend $<0.02$ ) (Table 2).

As shown in Table 2, women were always less likely to meet the recommended PA levels compared to men ( $\mathrm{p}$ for trend $<0.0001$ ). This significant difference was seen across all ethnic groups (Figure 1). Likewise, the prevalence ratio's decreased with increasing age from 62.7 in the younger individuals to 42.6 in the oldest participants ( $\mathrm{p}$ for trend $<0.0001$ ). With $61.6 \%$, the Creole population had the highest percentage of individuals meeting the recommended PA level $(\mathrm{p}=0.001)$, whereas the lowest percentage was reported by the Javanese population. Finally, the lowest percentage of participants meeting the recommend PA level was found in the group with no household income and no formal education. According to the guidelines, the PA recommendations can be met by being active only within one domain or by being active within two or three domains combined. Table 3 depicts the quartile values for the percentage that one domain contributes to the overall PA of the participants that met the recommendations. Within all areas the working domain contributes for the most part to the overall PA, though the median value is the highest within the RIA (86.8\%), followed by the RCA (73.6\%). Table 3 also shows that leisure time activity has a low contribution to the overall PA, with the $75^{\text {th }}$ percentile at $28 \%$ for the overall population and at $34.5 \%, 13 \%$ and $1.3 \%$ for the UCA, RCA and IRA respectively. In all ethnic groups, the working domain contributed the most to the total PA. The highest median value was found for the Maroon population $76.9 \%$, whereas the lowest value was found for the mixed ethnicity group $49.4 \%$. For these two ethnic groups the $75^{\text {th }}$ percentile for leisure time PA was respectively $6.8 \%$ and $44.4 \%$ which were the lowest and highest reported values. With a median value of $7.7 \%$ the transport domain has the lowest contribution to the overall PA level for the Javanese population that meets the recommended level of PA (Table 3).

\section{Discussion}

Our study showed that within a representative multiethnic population of Suriname, only $55.5 \%$ of the population met the recommended PA levels based on the WHO guidelines. In general, women were less active compared to men and the proportion of individuals meeting the recommendations decreased with increasing age, even after adjusting for important covariates. Further, people living 
Table 1 Demographic Characteristics of the total population and of the subjects by area

\begin{tabular}{|c|c|c|c|c|c|}
\hline & Total population (\%) & UCA (\%) & RCA (\%) & RIA (\%) & $p$-value \\
\hline Total population & $4487(100)$ & $2312(76.0)$ & $1482(15.9)$ & $693(8.1)$ & \\
\hline \multicolumn{6}{|l|}{ Gender } \\
\hline Men & $1654(48.6)$ & $882(48.4)$ & $585(51.8)$ & $187(44.5)$ & 0.06 \\
\hline \multicolumn{6}{|l|}{ Age categories } \\
\hline Mean age (years) & $36.2+/-13.6$ & $36.2+/-13.9$ & $36.9+/-13.6$ & $35.6+/-12.8$ & \\
\hline $15-24$ & $821(25.0)$ & $405(25.3)$ & $248(24.2)$ & $168(23.2)$ & 0.53 \\
\hline $25-34$ & $1012(23.5)$ & $494(23.4)$ & $316(21.9)$ & $202(27.3)$ & \\
\hline $35-44$ & $982(20.8)$ & $507(20.3)$ & $347(22.1)$ & $128(22.2)$ & \\
\hline $45-54$ & $981(19.6)$ & $532(19.7)$ & $327(19.9)$ & $122(17.6)$ & \\
\hline $55-64$ & $691(11.2)$ & $374(11.2)$ & $244(11.9)$ & $73(9.7)$ & \\
\hline \multicolumn{6}{|l|}{ Ethnic groups } \\
\hline Creole & $594(13.0)$ & $351(14.7)^{a}$ & $242(11.3)^{b}$ & $1(0)^{c}$ & $<0.001$ \\
\hline Hindustani & $1195(33.4)$ & $832(36.6)^{a}$ & $362(34.9)^{a}$ & $1(0)^{b}$ & \\
\hline Javanese & $842(16.4)$ & $399(15.4)^{a}$ & $443(29.6)^{b}$ & $0(0)^{c}$ & \\
\hline Maroon & $1147(19.3)$ & $267(13.0)^{a}$ & $195(8.7)^{b}$ & $685(99.5)^{c}$ & \\
\hline Mix ethnicity & $706(18.0)$ & $463(20.3)^{a}$ & $240(15.4)^{b}$ & $6(0.5)^{c}$ & \\
\hline \multicolumn{6}{|l|}{ Economic status* } \\
\hline No income & $390(6.4)$ & $99(3.9)^{\mathrm{a}}$ & $58(3.2)^{\mathrm{a}}$ & $233(36.6)^{b}$ & $<0.001$ \\
\hline$<$ SRD 800/month & $695(13.4)$ & $295(12.2)^{a}$ & $254(15.9)^{\mathrm{b}}$ & $146(19.9)^{b}$ & \\
\hline SRD 800-1499/month & $1391(29.1)$ & $683(28.1)^{\mathrm{a}}$ & $550(36.7)^{\mathrm{b}}$ & $158(23.4)^{\mathrm{a}}$ & \\
\hline SRD 1500-2199/month & $561(13.2)$ & $329(13.8)^{a}$ & $210(15.6)^{a}$ & $22(3.8)^{b}$ & \\
\hline SRD 2200-2899/month & $186(4.7)$ & $155(5.1)^{\mathrm{a}}$ & $65(4.5)^{\mathrm{a}}$ & $6(1.1)^{\mathrm{b}}$ & \\
\hline > SRD 2900/month & $338(9.6)$ & $247(11.2)^{\mathrm{a}}$ & $78(5.6)^{b}$ & $13(2.2)^{c}$ & \\
\hline \multicolumn{6}{|l|}{ Education level* } \\
\hline No education & $389(5.8)$ & $68(2.7)^{a}$ & $44(2.0)^{\mathrm{a}}$ & $277(41.7)^{b}$ & $<0.0001$ \\
\hline Low level & $3234(71.5)$ & $1613(70.4)^{a}$ & $1225(85.1)^{\mathrm{b}}$ & $396(55.1)^{c}$ & \\
\hline High level & $805(21.5)$ & $597(25.6)^{a}$ & $196(11.9)^{b}$ & $12(1.6)^{c}$ & \\
\hline \multicolumn{6}{|c|}{ Meeting recommended level of PA } \\
\hline Moderate-vigorous PA level & $2377(55.5)$ & $1222(55.7)^{\mathrm{a}}$ & $816(57.9)^{\mathrm{a}}$ & $339(49.1)^{b}$ & 0.02 \\
\hline
\end{tabular}

in the RIA were less likely to meet the recommended PA levels. When comparing the ethnic groups, the lowest percentage of individuals meeting the recommendations was within the Javanese population.

Our findings are in line with data from the Caribbean region, where between $51.9 \%-74.5 \%$ of the population met the recommended PA level [29] and are somewhat lower than data from the American region, where, irrespective of gender, $56.7 \%$ of the population met the recommended PA level [7]. Guthold et al. also compared PA data from 4 South American countries (Brazil, Ecuador, Paraguay and Uruguay) and reported that between $64.6 \%$ - $82 \%$ of men and between $69.8 \%$ $79.1 \%$ of women met the recommendations [13]. Compared to the data from Guthold et al., our findings for men are within the range and for women are lower than the reported range. As noted from these studies there exists a great variance in PA behavior between countries and between different regions [7,12,13]. This could be attributed to several factors including the use of different questionnaires. Guthold et al. used the short form of the international physical activity questionnaire (IPAQ) [13], whereas other studies used the long form of IPAQ or the GPAQ [7,29]. 
Table 2 Percentage and unadjusted and adjusted prevalence ratios for meeting the recommended PA level

Weighted Unadjusted PR Adjusted PR

$\%$

(Cl)

(Cl)

Area $^{\mathrm{a}}$

Urban coastal

\section{7}

Rural coastal

57.9

1 (reference)

1 (reference)

Rural interior

49.1

$1.09(1.01-1.17)$

1.06 (0.99-1.15)

$0.86(0.77-0.97)$

$0.86(0.74-0.99)$

Gender ${ }^{b}$

Male

Female

62.4

49.0

1 (reference)

0.77 (0.73-0.82)

1 (reference)

$0.78(0.74-0.84)$

Age categories ${ }^{c}$

15-24

25-34

35-44

45-54

55-64

Ethnicity $^{d}$

Hindustani

Maroon

Mix ethnicity

Javanese

Creole

62.7

54.7

1 (reference)

0.86 (0.79-0.93)

1 (reference)

0.89 (0.82-0.97)

$0.85(0.78-0.93)$

$0.69(0.61-0.79)$

1 (reference)

$0.91(0.83-0.99)$

$0.96(0.87-1.05)$

$0.93(0.85-1.02)$

$1.07(0.98-1.17)$

0.87 (0.80-0.95)

$0.91(0.83-0.99)$

$0.85(0.78-0.93)$

$0.71(0.62-0.81)$

1 (reference)

$1.02(0.91-1.14)$

$0.96(0.88-1.05)$

$0.92(0.84-1.00)$

$1.07(0.98-1.17)$

Economic status ${ }^{\mathrm{e}}$

No income $\quad 33.9$

< SRD 800/month

SRD 800-1499/

month

SRD 1500-2199/ $\quad 57.4$

month

SRD 2200-2899/ 57.9

month

> SRD 2900/month

52.5

Education level ${ }^{\mathrm{f}}$

No education

Low level

38.6

57.5

53.6

High level

The weighted percentages are calculated for the 4487 subjects, whereas the prevalence ratio analysis is based on 3255 subjects because of missing data for the economic status. $\mathrm{PR}=$ Prevalence ratio $; \mathrm{Cl}=$ Confidence interval

${ }^{a}$ Adjusted for gender, age category and ethnicity.

${ }^{\mathrm{b}}$ Adjusted for area, age category and ethnicity.

'Adjusted for gender, area and ethnicity.

${ }^{\mathrm{d}}$ Adjusted for area, gender and age category.

${ }^{\mathrm{e}}$ Adjusted for area, gender, age category and ethnicity.

${ }^{f}$ Adjusted for area, gender, age category and ethnicity.

Recommended PA level conform the World health organization guidelines.

The GPAQ, used in our study, has previously been used in the African region, India and the Czech Republic $[6,14,30,31]$. Compared to these countries the Surinamese population seems less active than those in the African region or in the Czech Republic but scores better compared to India. This variance could be explained by several other factors including the age categories selected within the studies [13]. The participants selected in respectively Czech republic, the African region and India were between 18-90 years, 24-69 years and 20 years and older. Also cultural differences in interpreting the questionnaire, and the inclusion of different areas could influence the variance [19,31], so comparisons require caution.

Comparing different areas some studies reported a higher prevalence of PA within the rural area than the urban area [13,14,32], whereas others found the opposite [19]. Our results showed that, compared to the UCA, the proportion of people in the RIA meeting the recommended PA level is lower $(p<0.05)$, whereas the proportion of people in the RCA is higher $(p>0.05)$. This difference could be attributed to a difference in economic status and/or education level, since these covariates have been shown to be associated with PA [33-35]. Within our population the economic status was significantly different between the 3 areas, where the proportion of people within almost every income category differed between the areas. This was also seen for the education level, where $41.7 \%$ of the RIA population had no formal education level. However some caution might be warranted as a large proportion of the population (33\%) did not give information on their economic status and education level. Even though, Dutch is the official language in Suriname and in school, only $5.7 \%$ of the RIA population $(80.3 \%$ of the total population) was interviewed in Dutch. As the interviewers were also fluent in speaking the native languages of the RIA, they translated the questionnaire when needed. In case further clarification of a question was needed, showing cards were used. Furthermore, there is also a significant difference between the areas for the ethnic groups, where $99 \%$ of the Maroon population lives in the RIA. These covariates might have influenced the difference found between areas and further investigation is needed.

In agreement with others, [5,6,12,13,30,31,36] we observed that a lower proportion of women met the recommended PA level $(\mathrm{p}<0.05)$, which remained significant after adjusting for covariates. Comparison of ethnic groups showed that the lowest percentage of women meeting the recommended PA level was found within the Javanese population. Further, older people were always less likely to meet the recommended levels of PA which is also a consistent finding in other populations [6,34].

Cardiovascular disease mortality data in Suriname shows that, Hindustani's account for $33.7 \%$ of all cardiovascular deaths, followed by the Creole population (28\%) [37]. This difference in mortality between ethnic populations can partly be explained by genetic 


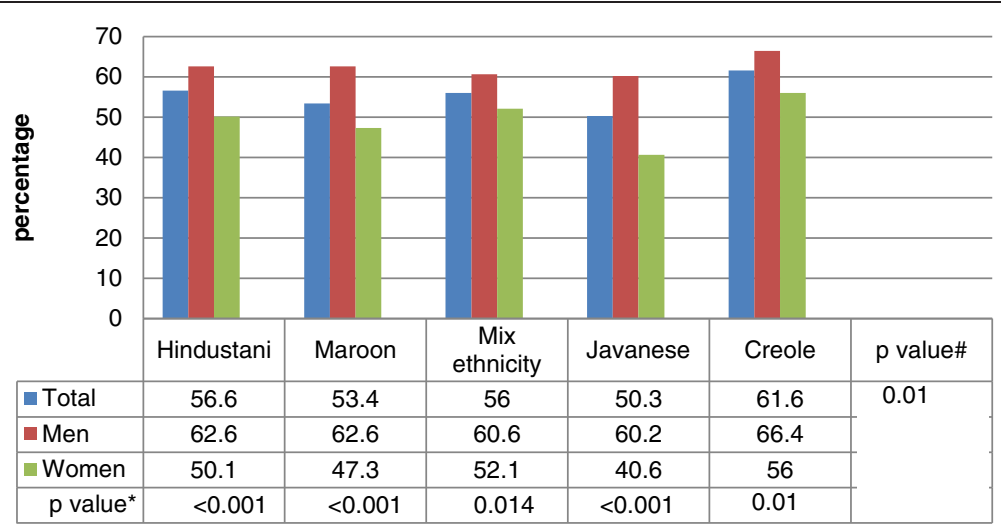

Figure 1 Percentage of total population, men and women meeting the recommended PA level per ethnic group. Legend: \#: significance level for difference between ethnic groups; ${ }^{*}$ significance level for difference between men and women.

variations [38] but most likely also by differences in lifestyle [39]. Therefore, in a multi-ethnic population, like in Suriname, an adequate evaluation of PA behavior in relation to the ethnic and cultural differences is needed. In our study, a lower proportion of Hindustani's met the recommended PA level compared to the Creole population, which was similar to results from The Netherlands [11]. Furthermore, we found the lowest proportion of individuals being sufficiently active among the Javanese population $(\mathrm{p}=0.07)$. Unfortunately, to the best of our knowledge, there are no data available on the prevalence of PA among Javanese communities outside Suriname which makes comparisons difficult. In order to develop effective PA intervention progams it is important to take these ethnic and cultural differences in PA into account [40].

For the development of PA intervention programs, it is furthermore recommended to investigate the different domains of PA, since different associations have been found for each of the separate domains with CVD mortality [41]. Prior studies conducted in India [32] and Mozambique [31], reported that in the rural areas , the working domain contributed more to the overall PA. That is, individuals living in the rural areas were more physically active in the working domain compared to the urban regios [31]. Our results also showed that the working domain had a bigger contribution to the overall PA level within the RIA compared to the two other areas. Since $99 \%$ of our population within the RIA is made up of the Maroon ethnic group, this high contribution of the working domain to the overall PA is also seen within this ethnic group. Within the RIA there is still a need for physically demanding labour and less time for leisure time activities compared to the fast growing UCA, where there are more sedentary working activities and increasing use of motorized transportation. With a very low contribution of the leisure time domain to the PA level for the total population and since participation in leisure time PA has been associated with an increase in life expectancy [42] it is important to focus on interventions to increase leisure time PA.

Our study has some limitations that need to be taken into consideration. First, the results are based on selfreported information which is sensitive for overestimation or recall bias [43-45]. Furthermore, since being physically active is a socially preferable activity, the use of questionnaires may lead to social desirability bias $[43,45]$. In order to identify if the observed differences in meeting the recommended PA level between the areas, ethnic groups and age categories in our study is not only based on the administration of the questionnaire and its inherent limitations, objective measurement of PA might be warranted in future research. Several objective and relatively affordable activity monitors have been identified and have been shown to be reliable and valid in measuring PA behavior [43]. However, also these objective measurements have their limitations that need to be taken into consideration when using these tools for future research for PA surveillance [46].

Secondly, seasonal variations have been reported to influence PA behavior [43]. Suriname is located in the tropical region of South America and experiences only small seasonal variations, which are mainly characterized by differences in rainfall and not by temperature or humidity. Hence, based on the distribution of rainfalls 4 seasons are identified for Suriname. These are: (a) the short wet season (beginning of December - beginning of February), (b) the short dry season (beginning of February - end of March), (c) the long wet season (beginning of April - mid of August), (d) the long dry seasons (mid of August - end of November) 
Table 3 Contribution of the three domains to the overall physical activity per area and ethnicity

\begin{tabular}{|c|c|c|c|c|c|}
\hline & & & $\begin{array}{l}25 \text { th } \\
\text { quartile }\end{array}$ & Median & $\begin{array}{l}\text { 75th } \\
\text { quartile }\end{array}$ \\
\hline \multirow{3}{*}{\multicolumn{2}{|c|}{ Total population }} & Work & 4.7 & 63.6 & 94.1 \\
\hline & & Transport & 0 & 12.7 & 45.5 \\
\hline & & $\begin{array}{l}\text { Leisure } \\
\text { time }\end{array}$ & 0 & 0 & 28 \\
\hline \multirow[t]{9}{*}{ Area } & \multirow[t]{3}{*}{ Work } & UCA & 0 & 57.1 & 93.2 \\
\hline & & RCA & 14.6 & 73.6 & 94.8 \\
\hline & & RIA & 66.7 & 86.8 & 98.2 \\
\hline & \multirow[t]{3}{*}{ Transport } & UCA & 0 & 13.3 & 48.3 \\
\hline & & $\mathrm{RCA}$ & 0 & 14.3 & 45.6 \\
\hline & & RIA & 0 & 10 & 24.3 \\
\hline & \multirow{3}{*}{$\begin{array}{l}\text { Leisure } \\
\text { time }\end{array}$} & UCA & 0 & 0 & 34.5 \\
\hline & & RCA & 0 & 0 & 13 \\
\hline & & RIA & 0 & 0 & 1.3 \\
\hline \multirow[t]{15}{*}{ Ethnicity } & \multirow[t]{5}{*}{ Work } & Hindustani & 6.4 & 66.6 & 95.8 \\
\hline & & Maroon & 9.0 & 76.9 & 95.8 \\
\hline & & $\begin{array}{l}\text { Mix } \\
\text { ethnicity }\end{array}$ & 0 & 49.4 & 86.9 \\
\hline & & Javanese & 22.2 & 72.6 & 96.3 \\
\hline & & Creole & 3.3 & 53.4 & 88.3 \\
\hline & \multirow[t]{5}{*}{ Transport } & Hindustani & 0 & 11.1 & 44.4 \\
\hline & & Maroon & 0 & 13.0 & 36.3 \\
\hline & & $\begin{array}{l}\text { Mix } \\
\text { ethnicity }\end{array}$ & 0 & 20 & 50 \\
\hline & & Javanese & 0 & 6.9 & 42.6 \\
\hline & & Creole & 1.1 & 19.5 & 46.6 \\
\hline & \multirow{5}{*}{$\begin{array}{l}\text { Leisure } \\
\text { time }\end{array}$} & Hindustani & 0 & 0 & 23.4 \\
\hline & & Maroon & 0 & 0 & 6.8 \\
\hline & & $\begin{array}{l}\text { Mix } \\
\text { ethnicity }\end{array}$ & 0 & 0 & 44.4 \\
\hline & & Javanese & 0 & 0 & 25.6 \\
\hline & & Creole & 0 & 0 & 36.3 \\
\hline
\end{tabular}

The values are the percentages that the working, transport or leisure time domain contributes to the overall physical activity. The median value, the first and third quartiles are given for the total population, per area and ethnicity. $\mathrm{UCA}=$ urban coastal area, $\mathrm{RCA}=$ rural coastal area, RIA = rural interior area.

[47]. Half of the recruitment period (3.5 months) involved the wet season (May - mid of August) and the other half (3.5 months) was performed during the large dry season (mid of August - September) and the short dry season (March - April). Therefore, as recruitment was equally balanced between the wet and dry seasons, we believe that seasonality will not have had a major impact on our overall results. Nevertheless, given these differences in rainfall, future research should investigate whether PA behavior differs according to seasonality in Suriname.
Finally, in our study, the validation of the translated GPAQ was based on the face-validation $[22,23]$ procedure whereby, as part of a pilot study, a small sample of participants was interviewed by a trained interviewer. The results were reviewed by a panel of experts. Further, Bull et al. showed earlier that overall the GPAQ provides reproducible data and showed a moderate - strong positive correlation with IPAQ and a poor to fair correlation for criterion validation procedure in low and middle income countries. Nevertheless, they concluded that the GPAQ is a suitable and acceptable instrument for monitoring physical activity in population health surveillance systems [21].

\section{Conclusion}

Approximately half of the Surinamese population meets the recommended PA level. A significant difference between men and women and also between people living in the RIA compared to the other areas is observed. Also within our population the proportion of subjects being physically active decreased with increasing age and the lowest percentage of PA is observed in the Javanese population. To our knowledge this is the first nationwide study performed in Suriname investigating the PA behavior and allowing an appropriate comparison between the areas, gender, age categories and ethnic groups. The obtained result can be used to identify groups and/or regions within the Surinamese population that need more attention or a different way of handling when designing or implementing PA intervention programs as part of a strategy to reduce the NCD burden.

\section{Abbreviations \\ CVD: Cardiovascular disease; GPAQ: Global physical activity questionnaire; IPAQ: International physical activity questionnaire; NCD: noncommunicable disease; PA: Physical activity; RCA: Rural coastal area; RIA: Rural interior area; STEPS: WHO STEPwise approach; UCA: Urban coastal area; WHO: World Health Organization.}

\section{Competing interests}

The authors declare that they have no competing interests.

\section{Authors' contributions}

All authors have made an intellectual contribution to this research project. SMB participated in data collection, performed the statistical analysis and data interpretation and drafted the paper. ISKK, CCFS and JRT designed the study, collected the data and participated in drafting the paper. VC contributed to the statistical analysis, data interpretation and writing of the paper. LV was responsible for critically reviewing the paper. All authors read and approved the final manuscript.

Authors' information

Luc Vanhees and Veronique Cornelissen are shared last author.

\section{Acknowledgement}

The study was financed by the Surinamese Government. Incentives for the respondents were provided by NV Consolidated Industries Corporation (CIC) and Staatsolie Maatschappij Suriname N.V. VC is supported as a postdoctoral research fellow by Research Foundation Flanders (FWO). 


\section{Author details}

'Department of Physical Therapy, Faculty of Medical Sciences, Anton de Kom University of Suriname, Paramaribo, Suriname. ${ }^{2}$ Department of Rehabilitation Sciences, Research Center for Cardiovascular Rehabilitation, Faculty of Kinesiology and Rehabilitation Sciences, Katholieke Universiteit Leuven, Leuven, Belgium. ${ }^{3}$ Department of Public Health, Faculty of Medical Sciences, Anton de Kom University of Suriname, Paramaribo, Suriname. ${ }^{4}$ Department of Physiology, Faculty of Medical Sciences, Anton de Kom University of Suriname, Paramaribo, Suriname.

\section{Received: 2 February 2015 Accepted: 27 April 2015}

Published online: 12 May 2015

\section{References}

1. WHO. Global status report on noncommunicable diseases 2014. Geneva: World Health Organization; 2014.

2. Warburton DE, Nicol CW, Bredin SS. Health benefits of physical activity: the evidence. CMAJ. 2006;174(6):801-9.

3. WHO. The global burden of disease 2004 update. Geneva: World Health Organization; 2008.

4. WHO. Global recommendations on physical activity for health. Geneva: World Health Organization; 2010

5. Scheers T, Philippaerts R, Lefevre J. Compliance with different physical activity recommendations and its association with socio-demographic characteristics using an objective measure. BMC Public Health. 2013;13:136.

6. Hamrik Z, Sigmundova D, Kalman M, Pavelka J, Sigmund E. Physical activity and sedentary behaviour in Czech adults: results from the GPAQ study. Eur J Sport Sci. 2014;14(2):193-8.

7. Hallal PC, Andersen LB, Bull FC, Guthold R, Haskell W, Ekelund U. Global physical activity levels: surveillance progress, pitfalls, and prospects. Lancet. 2012;380(9838):247-57.

8. Punwasi W. Doodsoorzaken Suriname 2010-2011. Paramaribo: Ministry of Health, Bureau Public Health; 2012.

9. Yusuf S, Reddy S, Ounpuu S, Anand S. Global burden of cardiovascular diseases: part II: variations in cardiovascular disease by specific ethnic groups and geographic regions and prevention strategies. Circulation. 2001;104(23):2855-64.

10. Dogra S, Meisner BA, Ardern Cl. Variation in mode of physical activity by ethnicity and time since immigration: a cross-sectional analysis. Int J Behav Nutr Phys Act. 2010;7:75.

11. de Munter JS, van Valkengoed IG, Agyemang C, Kunst AE, Stronks K. Large ethnic variations in recommended physical activity according to activity domains in amsterdam, the netherlands. Int J Behav Nutr Phys Act. 2010;7:85.

12. Bauman A, Bull F, Chey T, Craig CL, Ainsworth BE, Sallis JF, et al. The International prevalence study on physical activity: results from 20 countries. Int J Behav Nutr Phys Act. 2009;6:21.

13. Guthold R, Ono T, Strong KL, Chatterji S, Morabia A. Worldwide variability in physical inactivity a 51-country survey. Am J Prev Med. 2008;34(6):486-94.

14. Anjana RM, Pradeepa R, Das AK, Deepa M, Bhansali A, Joshi SR, et al. Physical activity and inactivity patterns in India - results from the ICMR-INDIAB study (Phase-1) [ICMR-INDIAB-5]. Int J Behav Nutr Phys Act. 2014;11(1):26.

15. Sugathan TN, Soman CR, Sankaranarayanan K. Behavioural risk factors for non communicable diseases among adults in Kerala, India. Indian J Med Res. 2008:127(6):555-63.

16. Arambepola C, Allender S, Ekanayake R, Fernando D. Urban living and obesity: is it independent of its population and lifestyle characteristics? Trop Med Int Health. 2008:13(4):448-57.

17. Abubakari AR, Lauder W, Jones MC, Kirk A, Agyemang C, Bhopal RS. Prevalence and time trends in diabetes and physical inactivity among adult West African populations: the epidemic has arrived. Public Health. 2009;123(9):602-14.

18. Abubakari AR, Bhopal RS. Systematic review on the prevalence of diabetes, overweight/obesity and physical inactivity in Ghanaians and Nigerians. Public Health. 2008;122(2):173-82.

19. Fan JX, Wen M, Kowaleski-Jones L. Rural-urban Differences in Objective and Subjective Measures of Physical Activity: Findings from the National Health and Nutrition Examination Survey [NHANES) 2003-2006. Prev Chronic Dis. 2014;11, E141.
20. Krishnadath I., Smits C., Jaddoe V., Hofman A., and Toelsie J. The Suriname health study:a national surveillance survey on non-communicable disease risk factors. JMIR Res Protoc . 2015. doi: 10.2196/resprot.4205.

21. Bull FC, Maslin TS, Armstrong T. Global physical activity questionnaire [GPAQ): nine country reliability and validity study. J Phys Act Health. 2009:6(6):790-804.

22. Portney LG, Watkins MP. Foundation of Clinical research: applications to practice 3rd ed. Upper Saddle River, New Jearsey: Pearson Prentice Hall; 2009. p. 97-115.

23. DeVon HA, Block ME, Moyle-Wright P, Ernst DM, Hayden SJ, Lazzara DJ, et al. A psychometric toolbox for testing validity and reliability. J Nurs Scholarsh. 2007;39(2):155-64.

24. WHO: Global physical activity questionnaire (GPAQ) analysis guide; Retrieved from http://www who.int/chp/steps/resources/GPAQ_Analysis_Guide.pdf. 2012.

25. Ministry of Social Affairs and Housing and General Bureau of Statistics: Suriname Multiple Indicator Cluster Survey 2010, Final Report: Paramaribo, Suriname. Paramaribo; 2014.

26. de Bruijne A, Schalkwijk A. The position and residential patterns of ethnic groups in Paramaribo's development in the twentieth century. New West Indian Guide. 2005;79(3\&4):239-71.

27. Heemskerk M. Scenarios in anthropology: reflections onpossible futures of the Suriname Maroons. Future. 2003:35:931-49.

28. Kopytoff B. The development of Jamaican maroon ethnicity. Caribbean Quartely. 1976;22(2/3):33-50.

29. WHO. Noncommunicable diseases country profile 2011. Geneva: World Health Organization; 2014.

30. Guthold R, Louazani SA, Riley LM, Cowan MJ, Bovet P, Damasceno A, et al. Physical activity in 22 African countries: results from the World Health Organization STEPwise approach to chronic disease risk factor surveillance. Am J Prev Med. 2011;41(1):52-60.

31. Padrao P, Damasceno A, Silva-Matos C, Prista A, Lunet N. Physical activity patterns in Mozambique: urban/rural differences during epidemiological transition. Prev Med. 2012;55(5):444-9.

32. Ranasinghe CD, Ranasinghe $P$, Jayawardena R, Misra A. Physical activity patterns among South-Asian adults: a systematic review. Int J Behav Nutr Phys Act. 2013;10:116.

33. Muntner P, Gu D, Wildman RP, Chen J, Qan W, Whelton PK, et al. Prevalence of physical activity among Chinese adults: results from the International Collaborative Study of Cardiovascular Disease in Asia. Am J Public Health. 2005;95(9):1631-6.

34. Teh $\mathrm{CH}$, Lim KK, Chan YY, Lim KH, Azahadi O, Hamizatul Akmar AH, et al. The prevalence of physical activity and its associated factors among Malaysian adults: findings from the National Health and Morbidity Survey 2011. Public Health. 2014;128(5):416-23.

35. Hallal PC, Victora CG, Wells JC, Lima RC. Physical inactivity: prevalence and associated variables in Brazilian adults. Med Sci Sports Exerc. 2003;35(11):1894-900.

36. Sallis JF. Age-related decline in physical activity: a synthesis of human and animal studies. Med Sci Sports Exerc. 2000;32(9):1598-600.

37. Punwasi W. Doodsoorzaken Suriname 2002-2007. Paramaribo: Ministry of Health, Bureau Public Health; 2009.

38. Ito K, Bick AG, Flannick J, Friedman DJ, Genovese G, Parfenov MG, et al. Increased burden of cardiovascular disease in carriers of APOL1 genetic variants. Circ Res. 2014;114(5):845-50.

39. Lucas A, Murray E, Kinra S. Heath beliefs of UK South Asians related to lifestyle diseases: a review of qualitative literature. J Obes. 2013:2013:827674.

40. Celis-Morales CA, Ghouri N, Bailey ME, Sattar N, Gill JM. Should physical activity recommendations be ethnicity-specific? Evidence from a cross-sectional study of South asian and European men. PLoS One. 2013:8(12):e82568.

41. Wanner M, Tarnutzer S, Martin BW, Braun J, Rohrmann S, Bopp M, et al. Impact of different domains of physical activity on cause-specific mortality: a longitudinal study. Prev Med. 2014;62:89-95.

42. Janssen I, Carson V, Lee IM, Katzmarzyk PT, Blair SN. Years of life gained due to leisure-time physical activity in the U.S. Am J Prev Med. 2013;44(1):23-9.

43. Warren JM, Ekelund U, Besson H, Mezzani A, Geladas N, Vanhees L. Assessment of physical activity - a review of methodologies with reference to epidemiological research: a report of the exercise physiology section of the European Association of Cardiovascular Prevention and Rehabilitation. Eur J Cardiovasc Prev Rehabil. 2010;17(2):127-39.

44. Canning KL, Brown RE, Jamnik VK, Salmon A, Ardern Cl, Kuk JL. Individuals underestimate moderate and vigorous intensity physical activity. PLoS One. 2014;9(5), e97927. 
45. Strath SJ, Kaminsky LA, Ainsworth BE, Ekelund U, Freedson PS, Gary RA, et al. Guide to the assessment of physical activity: Clinical and research applications: a scientific statement from the American Heart Association. Circulation. 2013;128(20):2259-79.

46. Pedisic Z, Bauman A. Accelerometer-based measures in physical activity surveillance: current practices and issues. Br J Sports Med. 2015;49(4):219-23.

47. Nurmohamed R, Naipal S, Becker C. Rainfall variability in Suriname and its relationship with the tropical Pacific ENSO SST anomalies and the Atlantic SST anomalies. Int J Climatol. 2007;27:249-56.

Submit your next manuscript to BioMed Central and take full advantage of:

- Convenient online submission

- Thorough peer review

- No space constraints or color figure charges

- Immediate publication on acceptance

- Inclusion in PubMed, CAS, Scopus and Google Scholar

- Research which is freely available for redistribution 